\title{
EUFEMISME DAN DISFEMISME DALAM KOMENTAR NETIZEN DI AKUN INSTAGRAM @ROSAMELDIANTI
}

\author{
Nisa UI Jannah ${ }^{1 *}$, Ratna Yulida Ashriyani ${ }^{2}$, Syamsinas Jafar ${ }^{3}$ \\ Universitas Mataram \\ *e-mail: nisauljannah03@gmail.com
}

\begin{abstract}
The problem studied in this research is how are the lingual forms, references, and functions of euphemisms and dysfemisms in netizen comments on theaccount Instagram @rosameldianti. The purpose of this study is to describe the lingual form, reference, and function of euphemisms and dysphemisms in netizen comments on theaccount Instagram @rosameldianti . Data collection is done by the method of listening and the method of documentation. The data were analyzed using the distributional method and the equivalent method. Based on the results of the study found 14 data on euphemism and 27 data on dysphemism. The types of euphemism references found are objects and animals, body parts, professions, diseases, activities, traits or circumstances, and people, while dysphemism references found are objects and animals, body parts, professions, diseases, events, activities, traits or circumstances. , places, and people. The functions of the use of euphemisms found are (1) smoothing speech that is considered taboo, (2) smoothing speech that can offend someone's feelings, and (3) smoothing speech as a form of respect, while the function of using dysphemism is (1) state taboo, not profanity, or immorality, (2) showing dislike for someone or something, (3) making fun of, criticizing, or insulting, (4) swearing or cursing, (5) showing disrespect or demeaning someone, (6 ) express anger or irritation, and (7) indicate something of low value.
\end{abstract}

Keywords: Euphemism, Dysphemism, Instagram

\section{PENDAHULUAN}

Saat berkomunikasi, baik secara lisan maupun tulis, secara langsung atau tidak langsung, individu dituntut untuk mampu menggunakan bahasa yang sopan, halus, serta menghindari penggunaan bahasa yang bersifat tabu (taboo words) agar tercipta hubungan yang harmonis antarsesama individu. Namun, seiring dengan perkembangan zaman yang didukung oleh kemajuan di bidang teknologi informasi dan komunikasi, masyarakat cenderung bersifat terbuka dan bisa dengan bebas menggunakan bahasa yang kurang baik atau kasar pada saat berkomunikasi khusunya ketika menggunakan jejaring sosial Instagram. Dalam ranah kajian semantik, istilah yang tepat untuk menggambarkan fenomena penggunaan bahasa yang sopan atau halus disebut eufemisme, sedangkan istilah yang tepat untuk menggambarkan fenomena penggunaan bahasa kasar atau kurang baik disebut disfemisme.
Fenomena penggunaan bentuk eufemisme dan disfemisme banyak ditemukan dalam komentar netizen pada akun Instagram para artis Indonesia. Salah satu akun Instagram milik artis Indonesia yang pada kolom komentarnya dipenuhi oleh komentar-komentar netizen yang mengandung bentuk eufemisme dan disfemisme adalah akun instagram @rosameldianti_. Pemilihan akun instagram @rosameldianti dilatarbelakangi oleh fakta bahwa Rosa Meldianti termasuk artis yang cukup rutin membagikan foto atau video kesehariannya pada akun instagram pribadinya sehingga banyak netizen yang mengomentari unggahan foto atau video tersebut dengan maksud untuk mengungkapkan rasa suka ataupun tidak suka.

Berdasarkan pemaparan di atas, maka dapat diungkapkan alasan mengapa penelitian ini perlu dilakukan. Pertama, tanpa disadari bahwa ketika sedang berkomunikasi melalui jejaring sosial, masyarakat seringkali menuliskan 
komentar-komentar yang mengandung bentuk disfemisme. Mengingat bahwa katakata yang mengandung disfemisme dapat menimbulkan nilai rasa kasar dan kurang sopan bahkan cenderung mendorong pada timbulnya konflik antarsesama pengguna jejaring sosial, maka penelitian ini perlu dilakukan agar masyarakat dapat mengenal dengan baik apa saja kata-kata yang bernilai rasa sopan (eufemisme). Dengan harapan bahwa pemakaian bentuk disfemisme dapat ditekan penggunaannya serta masyarakat lebih memilih menggunakan bentuk eufemisme untuk menjaga hubungan yang harmonis antarsesama pengguna jejaring sosial, khususnya Instagram.

Kedua, dalam komentar-komentar yang dituliskan netizen pada kolom komentar akunInstagram @rosameldianti_ banyak ditemukan bentuk eufemisme dan disfemisme yang cukup unik dan jarang sekali diketahui secara luas oleh masyarakat sehingga penelitian ini perlu dilakukan agar masyarakat mengetahui bentuk-bentuk eufemisme dan disfemisme tersebut, seperti ungkapan biji ketumbar, frasa papi tubang, pesun, dan lain-lain. Ketiga, belum ada penelitian yang secara khusus mengkaji penggunaan eufemisme dan disfemisme dalam komentar netizen pada akuninstagram@rosameldiantii.

Masalah yang diangkat dalam penelitian ini yaitu, "Bagaimanakah bentul lingual, jenis referensi, dan fungsi penggunaan eufemisme dan disfemisme dalam komentar netizen di akun Instagram @rosameldianti_”. Adapun manfaat penelitian yang diharapkan dari penelitian ini adalah: (a) Manfaat teoritis, yaitu bermanfaat untuk menambah wawasan bagi para pembaca tentang ilmu semantik, khususnya yang berkaitan dengan penggunaan bahasa eufemisme dan disfemisme, (b) Manfaat praktis, yaitu (1) bagi pembaca diharapkan mampu menggunakan eufemisme dan menghindari penggunaan disfemisme khususnya ketika menggunakan jejaring sosial agar tidak terjadi ketersinggungan, ketidakharmonisan, ketidaksenangan, serta perpecahan yang berujung pada sebuah konflik antar sesama pengguna jejaring sosial dan (2) bagi bidang pendidikan, penelitian ini diharapkan dapat menjadi bahan referensi bagi guru Bahasa dan Sastra Indonesia sebagai media pembelajaran yang diajarkan kepada siswasiswi di sekolah.

\section{LANDASAN TEORI}

\section{Semantik}

Kata semantik dalam bahasa Indonesia (Inggris: semantics) berasal dari bahasa Yunani sema (kata benda yang berarti "tanda" atau "lambang") dengan kata kerjanya, yaitu semaino yang berarti "menandai" atau "melambangkan" (Chaer, 2009:2). Kata semantik kemudian disepakati sebagai istilah yang digunakan untuk bidang linguistik, yaitu sebuah bidang yang mempelajari hubungan antara tanda-tanda linguistik dengan hal-hal yang ditandainya atau dengan kata lain, bidang studi dalam linguistik yang mempelajari tentang smakna atau arti dalam sebuah bahasa (Chaer, 2009:2). Sejalan dengan pendapat Chaer di atas, Aminuddin (2015:15) menyatakan bahwa semantik merupakan sebuah studi tentang makna. Makna merupakan bagian dari bahasa sehingga dapat ditarik kesimpulan bahwa semantik adalah bagian dari linguistik.

\section{Makna Referensial}

Menurut Djajasudarma (2021:14) makna refrensial merupakan makna yang memiliki hubungan secara langsung dengan kenyataan atau referen (acuan), makna referensial juga dapat disebut sebagai makna kognitif sebab memiliki sebuah acuan atau referen. Pendapat lain juga dituturkan oleh Aminuddin (2015:88) yang menyatakan bahwa makna referensial merupakan gambaran sebuah makna yang dihasilkan oleh unsur kebahasaan, baik kata, kalimat, maupun unsur lainnya yang berkaitan erat dengan unsur di luar bahasa, baik berupa realitas maupun pengalaman. Sebagai contoh, kata meja dan kursi 
termasuk ke dalam kata bermakna referensial sebab keduanya mempunyai referensi, yaitu sejenis perabot rumah tangga yang disebut "meja" dan "kursi" (Chaer, 2009:64).

\section{Eufemisme}

Istilah eufemisme berasal dari bahasa Yunani eu yang berarti bagus dan phemeoo yang berarti berbicara, dengan kata lain eufemisme berarti berbicara dengan menggunakan perkataan yang baik atau halus, yang memberikan kesan baik (Astuti, 2021:22). Menurut Santoso (2003: 48) eufemisme dapat diartikan sebagai penggunaan kata atau ungkapan yang dipandang memiliki nilai rasa sopan atau halus. Sejalan dengan pendapat Astuti dan Santoso di atas, Chaer (2009:144) mengatakan bahwa eufemisme termasuk dalam perubahan makna. Eufemisme merupakan gejala ditampilkannya kata-kata atau bentuk-bentuk yang dianggap memiliki makna yang lebih halus atau lebih sopan daripada yang digantikannya. Misalnya, kata penjara atau bui digantikan dengan ungkapan yang maknanya dianggap lebih halus, yaitu lembaga pemasyarakatan. Berbeda dengan Chaer, Djajasudarma (1993:78) berpendapat bahwa eufemisme termasuk ke dalam ranah kajian semantik, yakni pergeseran makna sebab dalam pergeseran makna tersebut terdapat upaya penggantian simbol baik berupa kata, frasa, maupun kalimat dengan bentuk baru sehingga maknanya akan bergeser.

\section{Disfemisme}

Istilah disfemisme berasal dari bahasa Yunani, yakni $d y s$ atau $d u s$ yang bersinonim dengan kata berarti bad, abnormal, dan difficult dalam bahasa Inggris yang bermakna buruk (Erlinawati, 2021:25). Jadi, dapat disimpulkan bahwa disfemisme adalah penggunaan kata-kata yang bermakna kasar atau mengungkapkan sesuatu yang bukan sebenarnya (Erlinawati, 2021:26). Disfemia atau disfemisme menurut Chaer (2009: 144) adalah usaha mengganti kata yang maknanya halus atau bermakna biasa dengan kata yang maknanya kasar. Misalnya, kata mencuri yang dipakai untuk menggantikan kata memperoleh atau mendapatkan seperti dalam kalimat Kontingen Suriname berhasil mencuri satu mendali emas dari cabang renang, penggunaan kata mencuri pada kalimat tersebut bernilai kasar sebab mencuri merupakan suatu tindak kejahatan yang dapat diancam dengan hukuman penjara. Menurut Alwi (dalam Ali Masri dkk, 2001:62) disfemisme digunakan untuk menghujat atau mengeraskan makna.

\section{Konteks Tuturan}

Konteks menurut Parera (dalam Rizkia, 2017:24) diartikan sebagai situasi yang terbentuk karena adanya setting, kegiatan, dan relasi. Pendapat lain dikemukakan oleh Tarigan (dalam Rindiyantika, 2018:33) yang menyatakan bahwa konteks merupakan latar belakang pengetahuan yang dipahami dan disetujui bersama oleh pembicara atau penulis dan penyimak atau pembaca serta menunjang interpretasi penyimak atau pembaca terhadap apa yang dimaksud oleh pembicara atau penulis dalam suatu tuturan tertentu. Menurut Leech (dalam Sutomo, 2015:28) konteks sebuah tuturan meliputi beberapa elemen, di antaranya adalah penyapa atau pesapa, konteks sebuah tuturan, tujuan sebuah tuturan, tuturan sebagai bentuk tindakan, dan tuturan sebagai produk suatu tindak verbal.

\section{METODE PENELITIAN}

Penelitian ini termasuk dalam jenis penelitian kualitatif bersifat deskriptif. Satori (dalam Heryana, 2019: 69-70) mengatakan bahwa penelitian kualitatif merupakan salah satu bentuk penelitian yang berupaya untuk memaparkan situasi sosial tertentu dengan cara mendeskripsikan kenyataan secara benar, serta dibentuk oleh kata-kata berdasarkan teknik pengumpulan dan analisis data yang relevan yang diperoleh dari situasi alamiah. Data penelitian berupa tuturan tertulis yang mengandung eufemisme dan disfemisme, 
baik berupa kata, frasa, maupun ungkapan yang digunakan oleh netizen ketika mengomentari foto atau video yang diunggah oleh pemilik akun instagram @rosameldianti_dalam kurun waktu dua tahun terakhir, yaitu tahun 2019 hingga tahun 2020. Sumber data dalam penelitian ini adalah tuturan tertulis yang diambil dari komentar netizen pada saat mengomentari unggahan foto atau video di akun Instagram @rosameldianti_. Metode pengumpulan data yang digunakan adalah metode simak dengan teknik lanjutan berupa teknik catat dan metode dokumentasi dengan teknik capture (tangkapan layar) melalui media smartphone. Metode analisis data yaitu, menggunakan metode distribusional dengan teknik lanjutan berupa teknik urai unsur terkecil dan teknik sisip, metode padan intralingual, dan metode padan ekstralingual. metode padan intralingual merupakan metode analisis data yang menganalisis data dengan cara menghubung-bandingkan unsur-unsur yang bersifat lingual, baik yang terdapat dalam satu bahasa maupun beberapa bahasa yang berbeda (Mahsun, 2017:120), sedangkan metode padan ekstralingual adalah metode analisis data yang digunakan untuk menganalisis unsur yang bersifat ekstralingual, yaitu menghubungkan masalah bahasa dengan hal yang berada di luar bahasa, seperti konteks tuturan (Mahsun, 2017: 123-125).

\section{PEMBAHASAN}

Berikut akan diuraikan hasil penelitian serta pembahasan terkait permasalahan yang telah dirumuskan, yaitu berkaitan dengan bentuk lingual, jenis referensi, dan fungsi penggunaan eufemisme dan disfemisme dalam komentar netizen di akun Instagram @rosameldianti_.

\section{Bentuk Lingual Eufemisme dan Disfemisme}

Pada bagian ini akan dipaparkan hasil penelitian tentang bentuk lingual penggunaan eufemisme dan disfemisme dalam komentar netizen ketika mengomentari unggahan foto maupun video di akun instagram miliki Rosa Meldianti. Data diperoleh berdasarkan komentar yang ditulis oleh para netizen pada kolom komentar akun instagram @rosameldianti_.

\section{a. Bentuk Lingual Eufemisme}

Variasi bentuk lingual eufemisme yang digunakan oleh para netizen dalam mengomentari unggahan foto maupun video di akun instagram @rosameldianti tersebut dibagi menjadi tiga, yaitu eufemisme berbentuk kata, frasa, dan ungkapan. Berikut adalah contoh datanya.

Tabel 1. Bentuk Lingual Eufemisme dalam Komentar Netizen di Akun Instagram @rosameldianti

\begin{tabular}{clc}
\hline No & \multicolumn{1}{c}{ Kutipan } & Bentuk Lingual Eufemisme \\
\hline $\mathbf{1}$ & @inggils_mas kapan sih udahan GIMMICK nya? Pengen & \multicolumn{1}{c}{ Kata dasar } \\
& $\begin{array}{l}\text { nonton lagi sindir }{ }^{2} \text { an teroos biar klarifikasi. Tuntut }{ }^{2} \text { an. Kan } \\
\text { seru yakan @_rosameldianti_ } \\
\text { (@anjani.dwiputri/DE/31/8/19). }\end{array}$ & \\
\hline $\mathbf{2}$ & $\begin{array}{l}\text { Si Meldi melet2 gitu kesan nya malah kaya perempuan } \\
\text { nakal bukan sexy (@kayls06_/DE/28/11/20). }\end{array}$ & Frasa \\
\hline $\mathbf{3}$ & $\begin{array}{l}\text { Tau nggak dari mana sampe mana aurat seorang wanita? } \\
\text { Kok perut di jual sih? Mau jadi } \text { kupu-kupu malam? } \\
\text { (@salwajihope/DE/19/2/20). }\end{array}$ & Ungkapan \\
\hline
\end{tabular}

Pada data (1) di atas, terdapat penggunaan eufemisme gimmick yang merupakan bentuk kata dasar dengan kategori nomina (kata benda). Kata gimmick (bahasa Inggris) atau gimik dalam bahasa Indonesia termasuk kata dasar karena hanya terdiri dari satu morfem bebas dan tidak memiliki satuan-satuan terkecil yang dapat dibagi. Kata gimmick atau gimik pada data (1) di atas termasuk bentuk 
eufemisme. Kata gimmick dapat diartikan sebagai 1) gerak-gerik tipu daya aktor untuk mengelabui lawan peran dan 2) sesuatu (alat atau trik) yang digunakan untuk menarik perhatian (KBBI Daring, 2021). Kata gimmick memiliki persamaan makna dengan kata rekayasa. Akan tetapi, meskipun memiliki makna yang sama, kata gimmick memiliki nilai rasa yang lebih halus dibandingkan dengan kata rekayasa. Berdasarkan makna dan sinonimnya, maka kata gimmick atau gimik digunakan untuk mengganti kata rekayasa. Kata tersebut memiliki makna yang sesuai dengan konteks kalimat yang digunakan dalam komentar yang dituliskan pemilik akun @anjani.dwiputri.

Frasa perempuan nakal pada data (2) merupakan sebuah frasa. Kata perempuan yang berkategori nomina (N) jika digabungkan dengan kata nakal yang berkategori adjektiva ( $\mathrm{Aj}$ ) akan membentuk sebuah frasa perempuan nakal. Untuk membentuk sebuah frasa kata perempuan tidak hanya digabungkan dengan kata nakal, tetapi juga bisa digabungkan dengan kata lain, sama halnya dengan kata nakal. Hal tersebut dapat dilihat dari contoh perempuan cantik, anak nakal, perempuan simpanan, dan wanita nakal. Data (2) merupakan eufemisme atau penghalusan makna. Frasa perempuan nakal dalam konteks kalimat pada data (2) bermakna perempuan yang suka melacurkan diri. Frasa perempuan nakal dalam konteks kalimat di atas digunakan untuk menggantikan kata pelacur, lonte, pekcun, perek, atau perempuan sundal yang dirasa memiliki nilai rasa tidak halus dan terkesan kasar jika dituturkan.

Pada data (3) di atas, terdapat penggunaan eufemisme berupa ungkapan kupu-kupu malam yang terdiri dari dua kata atau unsur yang berkategori nomina $(\mathrm{N})$. Dalam bentuk ungkapan, eufemisme kupukupu malam memiliki makna lain, yaitu pekerja seks komersial (PSK). Ungkapan kupu-kupu malam merupakan eufemisme atau penghalusan makna. Ungkapan kupukupu malam digunakan untuk menggantikan kata pelacur, pesun, dan perek. Penggunaan kata pelacur, pesun, dan perek dianggap memiliki nilai rasa yang kurang sopan karena dapat menyinggung perasaan orang lain. Oleh karena itu, untuk menghindari ketersinggungan antar penutur dan lawan tutur, maka kata pelacur, pesun, dan perek dapat digantikan dengan ungkapan kupu-kupu malam karena ungkapan tersebut memiliki makna yang sesuai dengan konteks kalimat pada data (3) di atas dan tentunya dapat menyamarkan makna sebenarnya yang terkandung dalam ungkapan tersebut.

\section{b. Bentuk Lingual Disfemisme}

Variasi bentuk lingual disfemisme yang digunakan oleh para netizen dalam mengomentari unggahan foto maupun video di akun instagram @rosameldianti_ tersebut dibagi menjadi tiga, yaitu eufemisme berbentuk kata dan frasa. Berikut adalah contoh datanya.

Tabel 2. Bentuk Lingual Disfemisme dalam Komentar Netizen di Akun Instagram @rosameldianti

\begin{tabular}{clc}
\hline No & \multicolumn{3}{c}{ Kutipan } & Bentuk Lingual Disfemisme \\
\hline $\mathbf{1}$ & $\begin{array}{l}\text { Emaknya bunting ape yee. Kasian bget mending masuk } \\
\text { ulang gih ke rahim emak lu. Bikin malu halu } \\
\text { (@omykappy260/DD/25/5/20). }\end{array}$ & Kata dasar \\
\hline $\mathbf{2}$ & $\begin{array}{l}\text { Besok umbar paha dan selangkangan burignya lagi mel? } \\
\text { *orang gila mah bebas shaaayyy } \\
\text { (@imarandan17/DD/14/1/20). }\end{array}$ & Kata berimbuhan \\
\hline $\mathbf{3}$ & $\begin{array}{l}\text { Fix meldi paling cebol paling jelek mukanya penuh pipi } \\
\text { semua (@halizanur_/DD/17/9/19). }\end{array}$ & Frasa \\
\hline
\end{tabular}

Dalam komentar yang dituliskan oleh pemilik akun@omykappy260 di atas, terdapat penggunaan disfemisme bunting. Kata bunting merupakan bentuk kata dasar 
dengan kategori verba (V). Kata bunting termasuk kata dasar sebab hanya terdiri dari satu morfem bebas serta tidak memiliki satuan-satuan terkecil lain yang dapat diuraikan. kata bunting pada data (1) memiliki persamaan makna dengan kata hamil yang berarti mengandung (KBIUP, 2011:154). Akan tetapi, meskipun kedua kata tersebut memiliki kesamaan makna, nilai rasa yang dihasilkan berbeda. Penggunaan kata bunting untuk menyebutkan keadaan seorang wanita yang sedang berbadan dua dinilai kurang sopan dan cenderung kasar sebab lazimnya kata bunting disandingkan dengan binatang atau hewan. Oleh sebab itu, untuk menjaga kesopanan dan kenyamanan maka kata bunting dalam konteks tuturan di atas dapat diganti dengan kata hamil.

Pada data (2) terdapat penggunaan disfemisme berbentuk kata berimbuhan yang berkategori nomina, yaitu kata selangkangan. Kata selangkangan termasuk kata berimbuhan sebab terdiri dari dua morfem, yaitu morfem selangkang dan morfem -an. Kata selangkangan telah mengalami proses afiksasi, yaitu pembubuhan sufiks -an sehingga menjadi selangkangan. Dengan terjadinya proses tersebut, kata selangkangan memiliki satuan-satuan yang lebih kecil. Kata selangkangan pada data (2) memberikan nilai rasa yang tidak sopan karena menyebutkan bagian pribadi yang dianggap tabu secara langsung. Untuk menghindari penyebutan secara langsung, masyarakat sering mengganti kata tersebut dengan bentuk eufemismenya, yaitu pangkal paha. Oleh karena itu, maka kata selangkangan termasuk dalam ranah disfemisme

Pada data (3) terdapat penggunaan eufemisme berbentuk frasa berupa paling cebol. Kata paling digabungkan dengan kata cebol yang berkategori adjektiva membentuk sebuah frasa paling cebol. Untuk membentuk sebuah frasa kata paling tidak hanya digabungkan dengan kata cebol, tetapi juga bisa digabungkan dengan kata lain, sama halnya dengan kata cebol. Hal tersebut dapat dilihat dari contoh paling cantik, paling pintar, terlalu cebol, dan cebol badannya. Frasa paling cebol pada data (3) secara leksikal bermakna kondisi tubuh yang sangat pendek. Frasa paling cebol bersinonim dengan frasa paling mungil. Berdasarkan konteks kalimat pada data (3), frasa paling mungil dapat digunakan untuk menggantikan frasa paling cebol yang dirasa memiliki nilai rasa tidak sopan atau tidak halus. Oleh karena itu, frasa paling cebol termasuk disfemisme.

\section{Refrensi Eufemisme dan Disfemisme}

Secara garis besar, ditinjau dari teori Wijana dan Rohmadi (2017:81), referensi disfemisme sama dengan referensi eufemisme, yaitu: (1) benda dan binatang, (2) bagian tubuh, (3) profesi, (4) penyakit, (5) aktivitas, (6) peristiwa, dan (7) sifat atau keadaan. Selain ketujuh referensi di atas, terdapat pula dua referensi eufemisme dan disfemisme lainnya yang sering digunakan, yaitu orang dan tempat. Berikut ini akan dipaparkan hasil penelitian mengenai jenis referensi yang ditemukan dalam komentar netizen di akuninstagram @rosameldianti_.

\section{a. Referensi Eufemisme}

Pada penelitian ini hanya ditemukan enam referensi eufemisme, yaitu benda dan binatang, bagian tubuh, profesi, aktivitas, sifat atau keadaan, dan orang. Berikut ini adalah beberapa contoh data yang ditemukan. 
LISDAYA: jurnal linguistik (terapan), sastra, dan budaya

Tabel 3. Referensi Eufemisme dalam Komentar Netizen di Akun Instagram @rosameldianti

\begin{tabular}{|c|c|c|}
\hline No & Kutipan & Jenis Refrensi Eufemisme \\
\hline 1 & 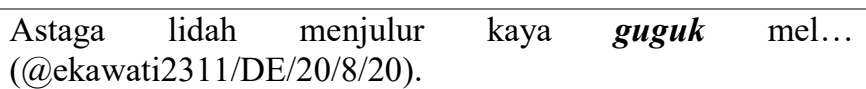 & Benda dan binatang \\
\hline 2 & $\begin{array}{l}\text { Tuh celananya nggak ada yg mahalan dikit pa mel, itu apem } \\
\text { sampe kaya bakpau tiga (@_heiidut/DE/9/2/20). }\end{array}$ & Bagian tubuh \\
\hline 3 & $\begin{array}{l}\text { Bajunya kalau untuk ukuran artis g bgttttt @ }{ }^{2} \text { rosameldianti } \\
\text { cocokan jadi asisten } \\
\text { (@nasigorengbuknurlina/DE/15/10/19). }\end{array}$ & Profesi \\
\hline 4 & $\begin{array}{l}\text { Goyang epilepsi ya mel? Gak ada enak2nya diliat } \\
\text { (@)sapimania_shop/DE/16/5/20). }\end{array}$ & Penyakit \\
\hline 5 & Bercinta yu beib (@endgieer/DE/15/10/19). & Aktivitas \\
\hline 6 & $\begin{array}{l}\text { Ternyata cowoknya juga luber-luber ya. Berarti di foto } \\
\text { editan semua (@olshop343_/DE/6/8/20). }\end{array}$ & Sifat atau keadaan \\
\hline 7 & $\begin{array}{l}\text { Jangan bekawan sama orang ga bener kek papi tubang mel. } \\
\text { Kamu org baik jangan campe terjerumus sama kek mereka } \\
(@ \text { meisaaa/DE/25/10/20). }\end{array}$ & Orang \\
\hline
\end{tabular}

Dalam komentar yang dituliskan pemilik akun@ekawati2311 di atas, terdapat bentuk eufemisme guguk. Guguk sendiri merupakan bentuk tiruan bunyi (onomatope) dari binatang anjing. Pada konteks kalimat di atas, penggunaan eufemisme guguk berfungsi untuk menghaluskan ucapan, pun dibeberapa kesempatan bentuk-bentuk tiruan bunyi seperti itu digunakan sebagai sarana pendidikan di dalam berbicara dengan anak-anak yang masih kecil. Berdasarkan penjelasan singkat di atas, maka bentuk tiruan bunyi guguk tersebut termasuk dalam jenis referensi binatang, yaitu anjing.

Dalam komentar yang dituliskan pemilik akun@_heiidut, terdapat bentuk eufemisme berupa kata apem atau apam (bentuk baku sesuai KBBI). Kata apem atau apam secara harfiah diartikan sebagai kue yang dibuat dari tepung beras, diberi ragi, santan, dan gula, bentuknya bulat, dimasak di wajan kecil di atas api, bara, atau kayu bakar yang relatif tidak panas (KBBI Daring, 2021). Akan tetapi, dalam konteks kalimat di atas, kata apem merujuk pada salah satu istilah gaul (slang) yang digunakan untuk menyebutkan alat kelamin wanita. Penggunaan kata apem pada kalimat di atas digunakan untuk menghindari penggunaan kata vulgar. Berdasarkan pemaparan singkat tersebut maka dapat disimpulkan bahwa kata apem pada konteks data (2) tersebut termasuk dalam jenis referensi bagian tubuh.

Pada data (3) terdapat penggunaan bentuk eufemisme berupa frasa asisten artis. Frasa tersebut termasuk ke dalam jenis referensi profesi karena frasa asisten artis merupakan pekerjaan yang dilakukan atau dijalani seseorang sebagai pendamping artis. Pada data (4) terdapat penggunaan eufemisme atau penghalusan makna berupa kata epilepsi. Kata tersebut termasuk dalam jenis referensi penyakit karena kata tersebut merujuk pada salah satu jenis penyakit dengan tanda-tanda penderita kehilangan kesadaran dan kejang seluruh tubuh lalu jatuh dan mulutnya berbuih (KBIUP, 2011:34).

Pada data (5) terdapat penggunaan eufemisme berupa kata bercinta. Kata bercinta jika diartikan secara harfiah akan memiliki arti menaruh rasa cinta. Akan tetapi dalam konteks kalimat di atas kata bercinta memiliki arti bergaul atau berhubungan intim (KBBI Daring, 2021) sehingga kata tersebut termasuk ke dalam jenis referensi aktivitas, yaitu melakukan aktivitas seksual. Pada data (6) terdapat penggunaan eufemisme berupa kata luberluber. Kata tersebut termasuk ke dalam jenis referensi keadaan karena menggambarkan keadaan seorang lelaki yang bersifat layaknya wanita. Selanjutnya, pada data (7) juga terdapat penggunaan eufemisme atau penghalusan makna berupa 
frasa papi tubang. Frasa papi tubang atau papi tua bangka termasuk ke dalam jenis referensi orang karena frasa tersebut merujuk pada sosok laki-laki yang sangat tua.

\section{b. Referensi Disfemisme}

Pada penelitian ini referensi disfemisme yang ditemukan mencakup keseluruhan jenis referensi, yaitu benda dan binatang, bagian tubuh, profesi, aktivitas, peristiwa, sifat atau keadaan, tempat dan orang. Berikut adalah contoh data referensi disfemisme yang ditemukan dalam komentar netizen di akun instagram @rosameldianti_.

Tabel 4. Referensi Disfemisme dalam Komentar Netizen di Akun Instagram@rosameldianti

\begin{tabular}{|c|c|c|}
\hline No & Kutipan & Jenis Refrensi Disfemisme \\
\hline 1 & $\begin{array}{l}\text { Wkwk skrg begini ntar sok juga posting pake beha ama } \\
\text { kancut atau pamer tokek (@rievenakiarap/DD/14/1/20). }\end{array}$ & Benda dan binatang \\
\hline 2 & $\begin{array}{l}\text { Murahan banger susu di umbar umbar ya awoh } \\
\text { (@ninnamalinna98/DD/15/07/20). }\end{array}$ & Bagian tubuh \\
\hline 3 & $\begin{array}{l}\text { Mirip lonte lagi jual memek } \\
\text { (@daling.daling.52012/DD/03/12/20). }\end{array}$ & Profesi \\
\hline 4 & $\begin{array}{l}\text { Lu lebih parah di ig kae cinderella aslinya penuh borok } \\
\text { muka lu. Sok cakep...lu (@innell2212/DD/12/11/19). }\end{array}$ & Penyakit \\
\hline 5 & Habis kencing cebok ros (@m.jhon93/DD/15/1/19). & Aktivitas \\
\hline 6 & $\begin{array}{l}\text { Ada berita kamu mati mel di riau yg kebakaran itu. } \\
\text { Katanya ada uler mati dikira kamu ternyata kamu kabur } \\
\text { cari aman, jd kamu ga setia kawan } \\
\text { (@jjoe64944/DD/25/919). }\end{array}$ & Peristiwa \\
\hline 7 & $\begin{array}{l}\text { Dari jawaban mu terlihat lah isi otak mu, dan kau lah yg } \\
\text { bego! (@dian.iskandar.3956/DD/2/9/19). }\end{array}$ & Sifat atau keadaan \\
\hline 8 & $\begin{array}{l}\text { Kayak orang peAk posenya...udah lah masuk penjara aja } \\
\text { nnti (@fenny_indriyani_tanjung/DD/1/1/19). }\end{array}$ & Tempat \\
\hline 9 & $\begin{array}{l}\text { Sok Bahagia lu...padahal buronan polisi } \\
\text { (@putridwi13/DD7/1/19). }\end{array}$ & Orang \\
\hline
\end{tabular}

Dalam komentar yang dituliskan pemilik akun@rievenakiarap di atas, terdapat bentuk disfemisme berupa kata beha dan kancut. Kata beha atau biasanya disingkat $B H$ bersionim dengan kata kutang yang bermakna baju dalam wanita untuk menutupi payudara (KBIUP, 2011:256). Kata beha termasuk dalam jenis referensi benda karena merujuk pada benda berupa baju dalam yang digunakan untuk menutupi area sensitif pada wanita. Selain kata beha, pada data (1) juga terdapat kata kancut yang juga bersinonim dengan kata celana dalam yang bermakna pakaian dalam berupa celana sebagai penutup kemaluan (KBIUP, 2011:71). Kata kancut termasuk dalam jenis referensi benda karena kata tersebut merujuk pada benda berupa pakaian dalam yang digunakan sebagai penutup kemaluan.
Pada data (2) terdapat penggunaan disfemisme atau pengasaran makna berupa kata susu yang bermakna payudara (KBIUP, 2011:554). Kata tersebut termasuk dalam jenis referensi bagian tubuh karena kata susu pada konteks kalimat di atas merujuk pada salah satu bagian tubuh yang dimiliki manusia, khususnya wanita. Pada data (3) terdapat penggunaan disfemisme atau pengasaran makna berupa kata lonte yang bermakna perempuan yang menjual diri atau wanita tunasusila (KBIUP, 2011:258). Kata lonte termasuk dalam jeni referensi profesi karena merujuk pada sebuah pekerjaan yang dijalani seseorang dengan cara menjual diri.

Pada data (4) terdapat penggunaan disfemisme berupa kata borok. Kata borok memiliki makna luka bernanah dan busuk karena infeksi (KBIUP, 2011:57). Kata 
tersebut termasuk ke dalam jenis referensi penyakit karena merujuk pada salah satu jenis penyakit yang disebabkan oleh infeksi pada luka yang menyebabkan luka tersebut bernanah dan busuk. Pada data (5) terdapat penggunaan disfemisme berupa kata kencing. Kata kencing termasuk ke dalam jenis referensi aktivitas karena kata tersebut merujuk pada suatu aktivitas mengeluarkan air seni (KBIUP, 2011:225).

Pada data (6) terdapat penggunaan disfemisme berupa kata mati. Kata mati bermakna sudah hilang nyawanya (KBIUP, 2011:306). Kata termasuk dalam jenis referensi peristiwa karena merujuk pada suatu kejadian atau peristiwa hilangnya nyawa seseorang (tidak hidup lagi). Pada data (7) terdapat penggunaan disfemisme atau pengasaran makna berupa kata bego. Kata tersebut termasuk ke dalam jenis referensi keadaan karena kata bego pada data (7) merujuk pada keadaan seseorang yang sangat bodoh atau tolol (KBBI Daring, 2021).

Pada data (8) terdapat penggunaan disfemisme berupa kata penjara. Kata penjara termasuk ke dalam jenis referensi tempat karena merujuk pada sebuah bangunan tempat mengurung orang hukuman (KBBI, 2011:400). Selain itu, pada data (9) juga terdapat penggunaan disfemisme atau pengasaran makna berupa kata kata buronan. Kata buronan termasuk ke dalam jenis referensi orang karena merujuk pada orang yang sedang diburu oleh polisi (KBBI Daring, 2021).

\section{Fungsi Eufemisme dan Disfemisme}

Fungsi eufemisme dalam penelitian ini akan dianalisis dengan menggunakan teori (Wijana dan Rohmadi, 2017) yang membagi fungsi eufemisme menjadi lima bagian, sedangkan fungsi disfemisme akan dianalisis menggunakan teori milik Kurniawati (2011) yang membagi fungsi disfemisme menjadi sepuluh bagian. Berikut ini adalah contoh data-data berupa fungsi penggunaan eufemisme dan disfemisme yang ditemukan dalam komentar netizen di akun instagram @rosameldianti_.

\section{a. Fungsi Eufemisme}

Terdapat tiga fungsi penggunaan eufemisme yang ditemukan dalam komentar netizen di akun instagram @rosameldianti_, yaitu menghaluskan ucapan sesuatu yang dianggap tabu, menghaluskan ucapan sesuatu yang dapat menyinggung perasaan seseorang, dan menghaluskan ucapan sebagai bentuk penghormatan. Berikut adalah contoh datanya.

Tabel 5. Fungsi Eufemisme dalam Komentar Netizen di Akun Instagram @rosameldianti

\begin{tabular}{cll}
\hline No & \multicolumn{1}{c}{ Kutipan } & \multicolumn{1}{c}{ Fungsi Eufemisme } \\
\hline $\mathbf{1}$ & $\begin{array}{l}\text { Jaga } \text { kehormatanmu } \text { sebagai wanita mbak } \\
\text { (@sarah_09sntn2/DE/22/12/20). }\end{array}$ & $\begin{array}{l}\text { Menghaluskan ucapan sebagai bentuk } \\
\text { penghormatan }\end{array}$ \\
\hline $\mathbf{2}$ & Mangkinnn chubby mell @cimolpalu/DE/26/5/20). & $\begin{array}{l}\text { Menghaluskan ucapan sesuatu yang } \\
\text { dapat menyinggung perasaan seseorang }\end{array}$ \\
\hline $\mathbf{3}$ & $\begin{array}{l}\text { Goyangan } \boldsymbol{P S K} \text { ketika merayu kliennya keknya } \\
\text { (@avatar30/DE/16/5/20). }\end{array}$ & $\begin{array}{l}\text { Menghaluskan ucapan sesuatu yang } \\
\text { dianggap tabu }\end{array}$ \\
\hline
\end{tabular}

Berdasarkan konteks tuturan pada data (1), kata kehormatanmu digunakan sebagai alat untuk menghaluskan ucapan sesuatu yang dianggap tabu. Konteks tuturan pada data (1) terjadi ketika Meldi mengunggah sebuah video berdurasi kurang dari satu menit yang memperlihatkan dirinya tengah melakukan gerakan twerking atau tarian dengan gerakan yang mengandung unsur sensualitas. Unggahan tersebut kemudian mendapat beragam komentar dari netizen, salah satunya berasal dari pemilik akun @)sarah_09sntn2. Penutur memberikan sebuah nasihat agar Meldi menjaga harga dirinya sebagai seorang wanita dengan 
tidak mempertontonkan auratnya. Penutur menggunakan kata 'kehormatanmu' sebagai alat untuk menghaluskan ucapan sehingga penutur tidak secara langsung mengungkapkan kata 'keperawanan' yang masih dianggap tabu di masyarakat.

Berdasarkan konteks tuturan pada data (2), kata chubbyy sebagai alat untuk menghaluskan ucapan sesuatu yang dapat menyinggung perasaan seseorang. Konteks tuturan tersebut terjadi ketika Rosa Meldianti mengunggah beberapa foto saat dirinya tengah memamerkan perubahan bentuk wajahnya sambil menuliskan caption "everything has changed." Unggahan foto tersebut kemudian mendapat beragam komentar dari netizen, salah satunya berasal dari pemilik akun (a) cimolpalu. Penutur menggunakan kata chubbyy untuk menggantikan kata tembam yang dianggap dapat menyinggung perasaan seseorang sebab faktanya seseorang tidak akan suka dan akan merasa tersinggung ketika disebut memiliki bentuk wajah yang tembam.

Berdasarkan konteks tuturan pada data (3), kata PSK digunakan sebagai alat untuk menghaluskan ucapan sebagai bentuk penghormatan. Konteks tuturan tersebut terjadi ketika Rosa Meldianti mengunggah sebuah video saat dirinya tengah membelakangi kamera sambil melakukan gerakan twerking. Unggahan foto tersebut kemudian mendapat beragam komentar dari netizen, salah satunya berasal dari pemilik akun @avatar30. Penutur menggunakan kata $P S K$ untuk menggantikan kata pelacur, perek, pekcun, atau lonte dengan tujuan untuk menghormati orang-orang yang memiliki atau menjalani profesi semacam itu.

\section{b. Fungsi Disfemisme}

Terdapat tujuh fungsi penggunaan disfemisme yang ditemukan dalam komentar netizen di akun instagram @rosameldianti_,yaitu: (1) menyatakan hal tabu, tidak senonoh, atau asusila, (2) menunjukkan rasa tidak suka terhadap seseorang atau sesuatu hal, (3) mengolokolok, mencela, atau menghina, (4) mengumpat atau memaki, (5) menunjukkan rasa tidak hormat atau merendahkan seseorang, (6) mengungkapkan kemarahan atau kejengkelan, dan (7) menunjukkan sesuatu yang bernilai rendah. Berikut adalah beberapa contoh datanya.

Tabel 6. Fungsi Disfemisme dalam Komentar Netizen di Akun Instagram @rosameldianti

\begin{tabular}{|c|c|c|}
\hline No & Kutipan & Fungsi Disfemisme \\
\hline 1 & $\begin{array}{l}\text { Ngewe’yuk@rosameldianti } \\
\text { (@,foeadwiendra/DD/22/12/20). }\end{array}$ & $\begin{array}{l}\text { Menyatakan hal yang bersifat tabu, } \\
\text { tidak senonoh, atau asusila }\end{array}$ \\
\hline 2 & $\begin{array}{l}\text { Terlalu editannya...muka lu mirip bool monyet mel } \\
\text { (@pipit sandra999/DD/2/5/20). }\end{array}$ & $\begin{array}{l}\text { Mengolok-olok, mencela, atau } \\
\text { menghina seseorang }\end{array}$ \\
\hline 3 & $\begin{array}{l}\text { @rosameldianti_duh bosan liat mukak loo di tv anjerrr } \\
\text { asu ingin ku katakan bangsat } \\
(@ \text { momoland ulala/DD/25/6/20). }\end{array}$ & Mengumpat atau memaki \\
\hline 4 & Artis berasa lonte (@ajje_ahmad/DD/26/8/20). & Merendahkan seseorang \\
\hline
\end{tabular}

Pada data (1) terdapat penggunaan disfemisme atau pengasaran makna, yaitu kata ngewe'. Kata ngewe' pada konteks kalimat di atas digunakan untuk menyatakan hal yang bersifat tabu, tidak senonoh, atau asusila. Konteks tuturan tersebut terjadi ketika Meldi mengunggah sebuah video berdurasi kurang dari satu menit yang memperlihatkan dirinya tengah melakukan gerakan twerking atau tarian dengan gerakan yang mengandung unsur sensualitas. Beragam komentar dari netizen turut meramaikan kolom komentar instagram Rosa Meldianti, salah satunya berasal dari pemilik akun@foeadwiendra. Dalam tuturannya, pemilik akun tersebut meminta Rosa Meldianti untuk melakukan hubungan intim dengannya. Penggunaan kata ngewe' pada data (1) termasuk kata 
yang bersifat tabu atau hal yang tidak senonoh untuk diutarakan.

Pada data (2) terdapat penggunaan disfemisme atau pengasaran makna, yaitu frasa bool monyet atau bol monyet. Frasa bool monyet pada konteks kalimat di atas digunakan untuk mengolok-olok, mencela, atau menghina seseorang. Konteks tuturan tersebut terjadi ketika Rosa Meldianti mengunggah foto dirinya yang telah diedit bersama dengan salah seorang artis asal Korea Selatan yang dikatakan mirip dengannya, yaitu Han Soo Hee. Pada foto tersebut Meldi juga menambahkan caption yang bertuliskan "12 12 lah" yang menggambarkan bahwa kecantikan yang dimilikinya setara dengan Han Soo Hee. Unggahan video tersebut mendapat beragam komentar dari netizen, ada yang memuji adapula yang menghina, salah satunya berasal dari pemilik akun @pipit_sandra999. Dalam tuturannya si pemilik akun menggunakan frasa bool monyet untuk mengolok-olok, mencela, atau menghina Rosa Meldianti yang dianggap terlalu memaksakan diri agar terlihat mirip dengan Han Soo Hee.

Pada data (3) terdapat penggunaan disfemisme, yaitu kata anjerrr, asu, dan bangsat. Ketiga kata pada konteks kalimat di atas digunakan untuk mengumpat atau memaki. Meskipun tidak disubstitusikan dengan bentuk eufemismenya, kata-kata yang digunakan untuk mengumpat atau memaki selalu bernilai kasar. Konteks tuturan tersebut terjadi ketika Rosa Meldianti mengunggah sebuah foto dirinya saat menjadi bintang tamu dalam acara Brownis di salah satu stasiun TV swasta tanah air (Trans TV). Unggahan foto tersebut mendapat beragam komentar dari netizen salah satunya berasal dari pemilik akun@momoland_ulala.@Dalam tuturannya si pemilik akun menggunakan kata anjerrr, asu, dan bangsat untuk mengumpat atau memaki sosok Rosa Meldianti yang selalu saja berseliweran di televisi hingga membuatnya bosan.

Pada data (4) terdapat terdapat penggunaan disfemisme, yaitu kata lonte.
Kata lonte pada konteks kalimat di atas digunakan untuk merendahkan seseorang. Konteks tuturan tersebut terjadi ketika Rosa Meldianti mengunggah sebuah video yang memperlihatkan dirinya sedang melakukan gerakan striptease. Tarian striptease sendiri mengarah pada unsur sensualitas karena gerakan-gerakan yang dilakukan cukup vulgar. Unggahan video tersebut mendapat beragam komentar dari netizen salah satunya berasal dari pemilik akun @ajje_ahmad. Dalam tuturannya si pemilik akun menggunakan kata lonte untuk merendahkan Rosa Meldianti yang dianggap sebagai artis tetapi berkelakuan layaknya seorang pekerja seks komersial yang suka mengumbar-umbar aurat yang tidak seharusnya dipertontonkan.

\section{PENUTUP \\ Simpulan}

Berdasarkan hasil penelitian dan pembahasan terhadap penggunaan eufemisme dan disfemisme dalam komentar netizen di akun Instagram @rosameldianti_dapat ditarik beberapa kesimpulan yaitu sebagai berikut ini. Pertama, analisis terhadap penggunaan eufemisme menunjukkan bahwa bentuk lingual eufemisme yang ditemukan adalah berbentuk kata (kata dasar, kata majemuk, kata berimbuhan, kata ulang), sedangkan analisis terhadap penggunaan disfemisme menunjukkan bahwa bentuk lingual disfemisme yang ditemukan adalah berbentuk kata (kata dasar dan kata berimbuhan) dan frasa. Kedua, jenis referensi eufemisme yang ditemukan berupa benda dan binatang, bagian tubuh, penyakit, profesi, aktivitas, sifat atau keadaan, dan orang, sedangkan referensi disfemisme yang ditemukan mencakup keseluruhan jenis referensi. Ketiga, fungsi penggunaan eufemisme yang ditemukan adalah: (1) menghaluskan ucapan sesuatu yang dianggap tabu, (2) menghaluskan ucapan sesuatu yang dapat menyinggung perasaan seseorang, dan (3) menghaluskan ucapan sebagai bentuk penghormatan, sedangkan fungsi penggunaan disfemisme 
yang ditemukan adalah: (1) menyatakan hal tabu, tidak senonoh, atau asusila, (2) menunjukkan rasa tidak suka terhadap seseorang atau sesuatu hal, (3) mengolokolok, mencela, atau menghina, (4) mengumpat atau memaki, (5) menunjukkan rasa tidak hormat atau merendahkan seseorang, (6) mengungkapkan kemarahan atau kejengkelan, dan (7) menunjukkan sesuatu yang bernilai rendah.

\section{Saran}

Berdasarkan hasil penelitian yang telah dilakukan maka penulis bermaksud untuk memberikan beberapa saran yang sekiranya dapat bermanfaat bagi tenaga pengajar maupun peneliti selanjutnya. Adapun saran yang peneliti ajukan adalah sebagai berikut ini. Pertama, tenaga pengajar diharapkan dapat menggunakan serta mengaplikasikan hasil penelitian ini sebagai salah satu bahan pembelajaran di sekolah terkait dengan penggunaan eufemisme dan disfemisme. Kedua, peneliti selanjutnya diharapkan dapat melanjutkan penelitian ini dengan melakukan pengkajian terhadap penggunaan eufemisme dan disfemisme dalam bentuk bahasa gaul sebab dalam penelitian ini ditemukan berbagai bentuk penggunaan bahasa gaul yang mengandung eufemisme dan disfemisme oleh netizen, seperti kata luber-luber, pesun, chubby, papi tubang, puki, dan sebagainya. Ketiga, peneliti selanjutnya diharapkan dapat melanjutkan penelitian ini secara lebih mendalam dengan menggunakan sumber data yang berbeda, seperti penggunaan eufemisme dan disfemisme dalam komentar netizen di media sosial twitter, facebook, tiktok, dan youtube.

\section{DAFTAR PUSTAKA}

Ali Masri, dkk. 2001.Kesinoniman Disfemisme dalam Surat Kabar Terbitan Palembang. LINGUA Jurnal Bahasa dan Sastra, 3: 62-82. Aminuddin. 2015. Semantik: Pengantar Studi Tentang Makna. Bandung: Sinar Baru Algensindo.
Astuti, Amelia Yuli. 2021. Eufemisme Bahasa Pendukung Capres RI Tahun 2014 dalam Akun Facebook: Kajian Sosiopragmatik. Tesis S2. Universitas Andalas.

Chaer, Abdul. 2009a. Pengantar Semantik Bahasa Indonesia. Jakarta: Rineka Cipta.

Djajasudarma. 1993. Semantik Pemahaman Ilmu Makna. Bandung: PT Eresco.

Djajasudarma, Fatimah. 2021. Semantik 2 (Relasi Makna, Paradigmatik, Sintagmatik, dan Derivasional). Bandung: Refika Aditama.

Erlinawati, Dewi. 2021. Penggunaan Disfemia dalam Komentar Para Netizen di Situs Online Kompas.com pada Rubrik "Politik. Skripsi. Universitas Negeri Yogyarakta.

Heryana, N. 2019. Eufemisme dan Disfemisme pada Media Berita Daring Republika: Perkembangan Kasus Setya Novanto Edisi Januari 2018. Jurnal Visi Ilmu Pendidikan, 11(1): 72-83.

Kurniawati, H. 2011. Eufemisme dan Disfemisme dalam Spiegel Online. Jurnal Literasi, 10 (1).

KBBI, 2021. Kamus Besar Bahasa Indonesia (KBBI). [Daring, diakses pada tanggal 29 Novmber 2021]. https://kbbi.kemndikbud.go.id/

Mahsun. 2017. Metode Penelitian Bahasa: Tahapan, Strategi, Metode, dan Tekniknya. Depok: Rajawali Pers.

Meity Taqdir Qodratillah dkk. 2011. Kamus Bahasa Indonesia untuk Pelajar. Jakarta: Badan Pengembangan dan Pembinaan Bahasa, Kementerian Pendidikan dan Kebudayaan.

Rindiyantika, Lastari. 2018. Kajian Elemen Fungsi Konteks Sosietal Dalam Menentukan Maksud Berkomunikasi Antar Mahasiswa dan Dosen FKIP Universitas Sanata Dharma Yogyakarta Tahun Akademik 2017/2018. Skripsi. Universitas Sanata Dharma. 
LISDAYA: jurnal linguistik (terapan), sastra, dan budaya Vol. 17 Nomor 2 edisi Juli-Desember 2021 - P-ISSN: 1858-408X E-ISSN: 2722-5186

Rizkia, Sofiana. 2017. Disfemia dalam Judul Berita-Berita di Surat Kabar Lombok Post. Skripsi. Universitas Mataram.

Santoso, Joko. 2003. Semantik. Diktat. Yogyakarta: Fakultas Bahasa dan Seni UNY.
Sutomo, J. 2015. Konteks, Referensi, dan Makna: Kajian Semantik. Dinamika Bahasa dan Budaya, 10(2).

Wijana, I Dewa Putu dan Romadi, Muhammad. 2017. Semantik Teori dan Analisis. Surakarta: Yuma Pustaka. 